\title{
S (2) \\ RNA Helicase DHX15 Decreases Cell Apoptosis by NF-kB Signaling Pathway in Burkitt Lymphoma
}

\section{Chen Yuan}

Fujian Medical University https://orcid.org/0000-0002-4158-137X

\section{Xianglei Chen}

Xiehe Affiliated Hospital of Fujian Medical University: Fujian Medical University Union Hospital

\section{Lili Pan}

Xiehe Affiliated Hospital of Fujian Medical University: Fujian Medical University Union Hospital

\section{Yuanmao Huang}

Zhangzhou Municipal Hospital of Fujian Province and Zhangzhou Affiliated Hospital of Fujian Medical University

\section{Yuanhua Cai}

Xiehe Affiliated Hospital of Fujian Medical University: Fujian Medical University Union Hospital

\section{Jinggang Li}

Xiehe Affiliated Hospital of Fujian Medical University: Fujian Medical University Union Hospital

\section{Yang Li}

Xiehe Affiliated Hospital of Fujian Medical University: Fujian Medical University Union Hospital

Shaoyuan Wang ( $\nabla$ shaoyuanwang@fjmu.edu.cn )

https://orcid.org/0000-0001-7428-8682

\section{Primary research}

Keywords: DHX15, Burkitt lymphoma, gene knockdown, apoptosis, NF-kB signaling pathway

Posted Date: October 26th, 2021

DOl: https://doi.org/10.21203/rs.3.rs-19743/v2

License: (c) (i) This work is licensed under a Creative Commons Attribution 4.0 International License.

Read Full License

Version of Record: A version of this preprint was published at Cancer Cell International on February 22nd, 2022. See the published version at https://doi.org/10.1186/s12935-021-02426-5. 


\section{Abstract}

Background: DHX15 is one of the RNA helicase family members involving in several biological processes. Studies have reported that overexpression of DHX15 is related to cancer progression. However, the role of DHX15 in Burkitt lymphoma (BL) and latent Epstein-Barr virus (EBV) infection remains to be elucidated.

Methods: Expression of DHX15 was measured in BL patient by immunohistochemical staining. In vitro study, a CCK-8 assay was used to analyze cell proliferation and flow cytometry was performed to assess cell cycle, apoptosis and mitochondria membrane potential. Members of NF-KB signaling pathway and apoptotic-related proteins expression were measured by western-blot. EBV latent infection products and RNA polymerase $\triangle$ transcripts expression were determined by quantitative real-time PCR and western-blot. In vivo study, HE, IHC, TUNEL and ISH assays were used to analyze the effect of DHX15 on subcutaneous tumor nodes formation.

Results: DHX15 was overexpressed in Burkitt lymphoma patients and tends to be associated with poor progression-free survival and poor overall survival. Knockdown of DHX15 significantly inhibits BL tumor growth, reduced cell proliferation, induced cell cycle arrest and increased cell apoptosis. Further analysis showed that canonical NF-KB signaling and its downstream targets, mitochondria and Caspase were involved in the increased cell apoptosis after $D H X 15$ gene knockdown. Furthermore, knockdown of DHX15 reduced EBV latent infection products expression and inhibited RNA polymerase $₫$ activity.

Conclusion: DHX15 may be an oncogene in the development of $\mathrm{BL}$ and a potential therapeutic target for the treatment of $\mathrm{BL}$ and latent $\mathrm{EBV}$ infection.

\section{Background}

Burkitt lymphoma (BL), first recognized as a clinical entity by Burkitt in 1958 (1), is a highly aggressive non-Hodgkin lymphoma (NHL) with extremely complex pathogenesis. All BL patients carry characteristic chromosomal translocations, resulting in constitutive expression of c-MYC protein. c-MYC is a transcription factor associated with cellular proliferation and determines cell cycle transition from $\mathrm{G} 1$ to $\mathrm{S}$ (2). Aside from chromosome translocation, Epstein-Barr virus (EBV) also plays an important role in the development of BL. EBV was first discovered in a BL tumor from a Ugandan patient by Anthony Epstein and Yvonne Barr via electron microscopy (3). More than $90 \%$ of BL patients are infected with EBV, most of them would enter latent infection (4-5). Latent EBV genomes express latent infection products, including six EBV-encoded nuclear antigens (EBNA), three latent membrane proteins (LMP), two EBV-

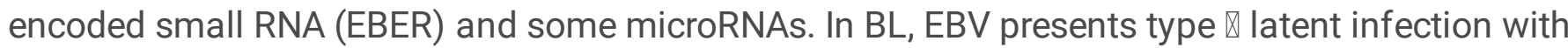
expression of EBNA-1, EBER-1 and EBER-2, which have been found to play important roles in the development of $\mathrm{BL}(6-9)$.

DEAH (Asp-Glu-Ala-His) box helicase 15 (DHX15) is one of the RNA helicase family members and plays an important role in several biological aspects. First, DHX15 participates in innate immune response against viral infection by regulating several signaling pathways (10-12). Second, DHX15 involves in 
modulating pre-mRNA and pre-rRNA splicing (13-17). Third, DHX15 plays a role in further processing of RNA polymerase $\otimes$ primary transcripts via interaction with La (SS-B) autoantigen (18). However, current researches of DHX15 in anti-virus mainly focused on RNA virus. It remains poorly understood whether DHX15 affects the expression of EBV latent infection products (EBNA-1, EBER-1, EBER-2) or participates in the development of BL.

Our previous study found that the $D H X 15$ gene was overexpressed in acute lymphoblastic leukemia (ALL) and acute myeloid leukemia (AML) patients. DHX15 was downregulated when AML patients achieved disease remission. $D H X 15$ gene knockdown in Jurkat and NB4 cells can induce cell apoptosis, arrest cell cycle and inhibit cell proliferation (19). In this study, we found that DHX15 promoted cell proliferation and tumor growth, inhibited cell apoptosis, and increased the expression of type $₫ \mathrm{EBV}$ latent infection products, suggesting that DHX15 might play an important role in pathogenesis of BL and be a potential therapeutic target for treating $\mathrm{BL}$.

\section{Material And Methods}

\section{Patient samples and follow-up}

The study was approved by the Fujian Medical University Ethics Committee. Sixty-three biopsy samples preserved in Pathology Department of Union Hospital Affiliated to Fujian Medical University from January 2008 to December 2017 were obtained with written informed consent from 31 patients diagnosed with BL and 32 patients diagnosed with noncancer lymphoid reactive hyperplasia (LRH). General and clinical characteristics of BL patients were shown in Table 1. Expressions of DHX15 were detected in each specimen via immunohistochemistry $(\mathrm{IHC})$. Diagnostic criteria for BL referred to World Health Organization (WHO) classification criteria for lymphohematopoietic tumors in 2008 (20). 
Table 1

General and clinical characteristics of BL patients with high or low DHX15 expression

\begin{tabular}{|c|c|c|c|c|}
\hline & NO. case & High DHX15(\%) & Low DHX15(\%) & $P$ \\
\hline \multicolumn{5}{|l|}{ Age } \\
\hline$<14$ years(\%) & 15 & $5(33.3)$ & $10(66.7)$ & 0.347 \\
\hline$\geq 14$ years(\%) & 16 & $8(50)$ & $8(50)$ & \\
\hline \multicolumn{5}{|l|}{ Gender } \\
\hline Male(\%) & 28 & 11(39.3) & 17(60.7) & 0.361 \\
\hline Female(\%) & 3 & $2(66.7)$ & 1(33.3) & \\
\hline \multicolumn{5}{|l|}{ WBC count } \\
\hline$\geq 10 \times 10^{9} / L(\%)$ & 9 & $3(33.3)$ & $6(66.7)$ & 0.626 \\
\hline$<10 \times 10^{9} / L(\%)$ & 21 & $9(42.9)$ & $12(57.1)$ & \\
\hline \multicolumn{5}{|l|}{ Anemia } \\
\hline Yes(\%) & 13 & $4(30.8)$ & $9(69.2)$ & 0.367 \\
\hline No(\%) & 17 & $8(47.1)$ & $9(52.9)$ & \\
\hline \multicolumn{5}{|l|}{ PLT count } \\
\hline$\geq 100 \times 10^{9} / L(\%)$ & 24 & $9(37.5)$ & $15(62.5)$ & 0.576 \\
\hline$<100 \times 10^{9} / L(\%)$ & 6 & $3(50)$ & $3(50)$ & \\
\hline \multicolumn{5}{|l|}{ Albumin $<35 \mathrm{~g} / \mathrm{L}$} \\
\hline Yes(\%) & 12 & $3(25)$ & $9(75)$ & 0.171 \\
\hline $\mathrm{No}(\%)$ & 18 & $9(50)$ & $9(50)$ & \\
\hline \multicolumn{5}{|l|}{$\mathrm{LDH}>245 \mathrm{U} / \mathrm{L}$} \\
\hline Yes(\%) & 22 & $9(40.9)$ & 13(59.1) & 0.382 \\
\hline No(\%) & 5 & $1(20)$ & $4(80)$ & \\
\hline \multicolumn{5}{|l|}{$\mathrm{UA}>420 \mu \mathrm{mol} / \mathrm{L}$} \\
\hline Yes(\%) & 15 & $5(33.3)$ & $10(66.7)$ & 0.597 \\
\hline No(\%) & 14 & $6(42.9)$ & $8(57.1)$ & \\
\hline \multicolumn{5}{|l|}{ EBER ISH(+) } \\
\hline Yes(\%) & 9 & $4(44.4)$ & $5(55.6)$ & 0.402 \\
\hline
\end{tabular}




\begin{tabular}{|lllll|}
\hline & NO. case & High DHX15(\%) & Low DHX15(\%) & $P$ \\
\hline No(\%) & 8 & $2(25)$ & $6(75)$ & \\
\hline B symptoms & & & & \\
\hline Yes(\%) & 10 & $3(30)$ & $7(70)$ & 0.429 \\
No(\%) & 20 & $9(45)$ & $11(55)$ & \\
\hline Stage & & & & 1.0 \\
\hline$-\square$ & 5 & $2(40)$ & $3(60)$ & \\
\hline$-\square$ & 20 & $8(40)$ & $12(60)$ & 0.683 \\
\hline Tumor diameter $\geq 10 \mathrm{~cm}$ & & & & \\
\hline Yes(\%) & 4 & $2(50)$ & $2(50)$ & $11(61.1)$ \\
\hline No(\%) & 18 & $7(38.9)$ & & \\
\hline
\end{tabular}

\section{Cell culture and lentiviruses infection}

The Raji cell line and Daudi cell line were purchased from the cell library of the Chinese Academy of Medical Science and maintained at $37^{\circ} \mathrm{C}$ in an atmosphere containing $5 \% \mathrm{CO}_{2}$ in RPMI-1640 supplemented with 10\% fetal bovine serum (FBS). RPMI-1640 and FBS were purchased from Hyclone company (USA) and TIAN JIN HAO YANG BIOLOGICAL MANUFACTURE CO.,LTD, respectively. DHX15-NCLentivirus, DHX15-shRNA-Lentivirus and polybrene were purchased from Shanghai GeneChem, China and maintained at $-80^{\circ} \mathrm{C}$. Four groups were set first (for Raji cells and Daudi cells): the blank control (CON) group, the blank control group with only polybrene at $8 \mu \mathrm{g} / \mathrm{ml}$ (ConP), the negative control (NC) group transfected with DHX15-NC-Lentivirus and the knockdown (KD) group transfected with DHX15-shRNALentivirus. The second experiments were divided into four groups (for Raji cells solely): the CON group with only pan Caspase inhibitor Z-VAD-fmk pretreatment for $2 \mathrm{~h}$ at $20 \mu \mathrm{mol} / \mathrm{L}(\mathrm{CON}+\mathrm{Z})$, the KD group transfected with DHX15-shRNA-Lentivirus with Z-VAD-fmk pretreatment for $2 \mathrm{~h}$ at $20 \mu \mathrm{mol} / \mathrm{L}(\mathrm{KD}+\mathrm{Z})$, the CON and the KD group.

For cell transfection, cells were seeded in 24-well plates with $5 \times 10^{4}$ cells per well containing $400 \mu$ l of medium for $2 \mathrm{~h}$ before transfection. Viral supernatants were supplemented with $8 \mu \mathrm{g} / \mathrm{ml}$ polybrene and incubated with target cells at a multiplicity of infection (MOI) at 80 (Raji cell line) or 120 (Daudi cell line) for $8 \mathrm{~h}$. After $72 \mathrm{~h}$ of transfection, cells were harvested for further experiments.

\section{RNA extraction and quantitative real-time PCR (qRT-PCR)}

Total RNA extraction was performed using TRIzol reagent (Invitrigen) according to the manufacturer's instructions. RNA concentration was measured by ultraviolet spectrophotometer. $1000 \mathrm{ng}$ of total RNA was subjected to reverse transcription to cDNA using the Verso cDNA kit (Thermo Fisher Scientific). qRTPCR was used to quantify the expression of DHX15, EBNA-1, EBER-1, EBER-2, 5S RNA, 7SL RNA and 
tRNA ${ }^{\text {tyr }}$ in Raji cells and $\beta$-actin was used as the loading control. qRT-PCR was performed on a 7500thermal cycle (ABI) using FastStart Universal SYBR Green Master Mix (Roche) with the following conditions: $95^{\circ} \mathrm{C}$ for $2 \mathrm{~min}, 40$ cycles of $95^{\circ} \mathrm{C}$ for $10 \mathrm{~s}$ and $60^{\circ} \mathrm{C}$ for $1 \mathrm{~min}$. All samples were run in triplicate, and the $2^{-\triangle C T}\left(\triangle C T=C T_{\text {target gene }}-\mathrm{CT}_{\beta \text {-actin }}\right)$ method was used to calculate the relative expression of target gene. Primer sequences were shown in Supplementary Table 1.

\section{Protein extraction and Western blot analysis}

For total protein extraction, cells were washed with cold phosphate buffer solution (PBS) and subsequently lysed in cold radioimmunoprecipitation assay (RIPA) lysis buffer containing $1 \mathrm{mM}$ phenylmethylsulfonyl fluoride (PMSF) and $1 \mathrm{mM}$ phosphatase inhibitor on ice for $30 \mathrm{~min}$. Clear protein extracts were obtained by centrifugation for $15 \mathrm{~min}$ at $4{ }^{\circ} \mathrm{C}$ and were quantified by ultraviolet spectrophotometer. Mitochondrial, nuclear and cytoplasmic proteins were separated from the cells according to the protocols supplied by Mitochondrial Isolation Kit for Mammalian cells and Tissues (Incent Biotechnologies, Inc), Nuclear and Cytoplasmic Protein Extraction Kit (Beyotime Biotechnology). Then, thermal denaturation of protein lysis containing $1 \times$ SDS loading buffer was conducted at $99^{\circ} \mathrm{C}$ for $10 \mathrm{~min} .80 \mu \mathrm{g}$ of protein mixed with SDS loading buffer was loaded per lane and separated by $12 \%$ SDSpolyacrylamide gel electrophoresis (SDS-PAGE). Proteins were transferred to nitrocellulose membrane

and nonspecific binding was blocked by $5 \%$ skim milk at room temperature for $90 \mathrm{~min}$. Membranes were incubated with corresponding primary antibody overnight at $4^{\circ} \mathrm{C}$. Then, membranes were washed with $1 \times$ TBST for $10 \mathrm{~min}$, three times, and then incubated with corresponding secondary antibody at room temperature for $45 \mathrm{~min}$ followed by washing the membrane with 1×TBST for $10 \mathrm{~min}$, three times. The immunoreactive bands were visualized using the ECL chemiluminescence detection kit for horseradish peroxidase (HRP). Images were acquired using X-ray film.

\section{Cell cycle assay}

Cell cycle assays were performed according to the instructions of the PI/RNase Cell Cycle Detection Kit (BD) as follows: cells were washed with cold PBS twice and fixed in $500 \mu 170 \%$ ethanol solution overnight at $4{ }^{\circ} \mathrm{C}$. After that, cells were washed with cold PBS twice again and resuspended in $100 \mu \mathrm{l}$ $\mathrm{Pl} / \mathrm{RNase}$ for $15 \mathrm{~min}$ in the dark followed by analysis of cell cycle by flow cytometry.

\section{Cell proliferation assay}

The Cell Counting Kit-8 (CCK-8) was used for measuring cell proliferation. 7,000 viable cells per well were seeded in 96-well plates in a final volume of $100 \mu \mathrm{l}$. Every $24 \mathrm{~h}$, a plate was subjected to measure cell proliferation by adding $10 \mu \mathrm{l}$ of CCK-8 solution for $2.5 \mathrm{~h}$ (Raji cells) or $3.5 \mathrm{~h}$ (Daudi cells) incubation at $37^{\circ} \mathrm{C}$. The absorbance at $450 / 630 \mathrm{~nm}$ was measured by a microplate reader. The experiment was repeated three times.

\section{Cell apoptosis assay}

Apoptosis assays were performed according to the instruction of the Annexin ख-PE/7-AAD Apoptosis Detection Kit (BD) as follows: cells were washed with cold PBS twice and then resuspended in $100 \mu \mathrm{l}$ 
1×Binding Buffer. Cells were stained with Annexin $\triangle-P E$ and 7-AAD for 15 min in the dark followed by measuring cell apoptosis by flow cytometry (BD).

\section{Mitochondrial transmembrane potential (MTP) assay}

Mitochondrial transmembrane potential (MTP) assays were performed according to the manuals of the JC-1 Mitochondrial Transmembrane Potential Detection Kit (BD) as follows: cells were harvested and resuspended in $500 \mu \mathrm{l} 1 \times \mathrm{JC}-1$ work solution and incubated for $15 \mathrm{~min}$ at $37^{\circ} \mathrm{C}$. After that, cells were washed with $1 \times$ Assay Buffer twice and resuspended in $500 \mu \mathrm{l} 1 \times$ Assay buffer followed by detecting the mitochondrial transmembrane potential by flow cytometry.

\section{Xenograft tumor formation}

All studies on mice were conducted in accordance with the National Institutes of Health "Guide for the Care and Use of Laboratory Animals" and were approved by the Fujian Medical Experimental Animal Care Committee. Eighteen six-week-old male BALB/c nude mice were housed in a temperature-controlled, pathogen-free animal facility with a $12 \mathrm{~h}$ light and $12 \mathrm{~h}$ dark cycle in the Animal Center of Fujian Medical University. The mice were divided into three groups randomly, CON, NC and KD group, in which untransfected Raji cells, Raji cells transfected with DHX15-NC-Lentivirus or Raji cells transfected with DHX15-shRNA-Lentivirus $\left(8 \times 10^{6}\right.$ cells in $200 \mu \mathrm{l} /$ animal) were respectively subcutaneously injected into the right flank. The mice were observed twice a week and sacrificed by cervical dislocation on day 42 . No anesthetic was used during the whole experiment.

\section{Hematoxylin-Eosin (HE) staining}

Xenograft tumors were fixed in 10\% neutral formalin overnight at room temperature followed by being dehydrated, transparent, embedded in paraffin and sectioned. The paraffin section of each specimen was deparaffinized, rehydrated and stained with hematoxylin and eosin according to the HE staining manufacturer's instructions. The staining results were observed under high magnification (200x) using Image Pro Plus 6.0 software.

\section{Terminal deoxynucleotidyl transferase (TdT) mediated nick end labeling (TUNEL) immunohistochemistry analysis}

TUNEL immunohistochemistry analysis was performed using the TUNEL Apoptosis Assay kit (Roche, South San Francisco, CA, US). $3 \mu \mathrm{m}$-thick sections were deparaffinized, rehydrated, quenched and treated with proteinase $\mathrm{K}$. TUNEL immunohistochemistry analysis was performed using TdT, digoxin-labeled dUTP and a two-stage TUNEL kit according to the manufacturer's instructions. The positive rate of each individual specimen was calculated as described above and was used to represent the apoptotic rate for an individual.

\section{Immunohistochemical analysis}

For patient samples, paraffin-embedded specimens were collected before chemotherapy from BL and noncancer LRH patients as described above. For xenograft tumors, paraffin-embedded specimens were 
prepared as described above. $3 \mu \mathrm{m}$-thick sections were deparaffinized, rehydrated and quenched. Immunohistochemical staining was performed using primary antibodies and a two-stage immunohistochemical kit according to the manufacturer's instructions. The number of all tumor cells and those with positive staining were calculated manually under high magnification (400x) using Image Pro Plus 6.0 software. Five fields were selected for each individual specimen to determine the percentage of tumor cells with positive staining among all tumor cells. The positive rate and staining intensity were used to represent the level of target protein expression. The primary antibodies against human DHX15 and Ki-67 were purchased from Abcam and EBAN-1 primary antibodies were purchased from Santa Cruz.

\section{EBER in situ hybridization (ISH) analysis}

EBER-ISH was applied to all xenograft tumors cases using digoxin labeled oligonucleotide probes to detect the expression of EBER-1 and EBER-2. $3 \mu \mathrm{m}$-thick sections were deparaffinized, rehydrated, quenched, treated with pepsase and prehybridization was performed for $2 \mathrm{~h}$. Sections were then incubated with EBER-1 and EBER-2 probes labeled with digoxin overnight. The next day, sections were washed with $2 \times S S C, 0.5 \times S S C$ and $0.2 \times S S C$ successively and then incubated with monoclonal mouse anti-digoxin. An ultrasensitive $A B C$ peroxidase mouse lgG staining kit and 3,3'-diaminobenzidine (DAB) were used for signal detection. The optical density (OD) value of each sample was calculated using Image Pro Plus 6.0 software.

\section{Statistical analysis}

The grading data of the two groups were compared with grade two and the independent sample rank sum test (Mann-Whitney $U$ ). The data were represented as the mean \pm standard deviation $(X \pm S D)$ and compared with Student's $t$ test or one-way ANOVA. The overall survival (OS) and progression-free survival (PFS) of BL patients were analyzed by the Kaplan-Meier method. All statistical analysis was performed using IBM SPSS software version 20.0 and a value of $P \otimes 0.05$ was considered statistically significant.

\section{Results}

\section{Higher expression of DHX15 in BL patients}

To determine the expression of DHX15 in BL patients, $\mathrm{IHC}$ was performed and the results suggested that DHX15 expression was significantly higher in BL patients than that in the noncancer LRH patients (Figures $1 \mathrm{~A}$ and $1 \mathrm{~B}$, and Table 2). Then, the BL patients were divided into low (IHC positive intensity were negative or $1+$ ) or high (IHC positive intensity were $2+$ or $3+$ ) DHX15 expression groups. Statistical analysis showed that there was no statistically significant difference for overall survival (OS, refers to the fact that the patient has not died from any cause) time and progression-free survival (PFS, refers to survival without progression of a particular disease) time between patients with high DHX15 expression and patients with low DHX15 expression (Figures 1C and 1D). 
Table 2

Expression of DHX15 protein in $\mathrm{BL}$ and noncancer $\mathrm{LRH}$ patients

\begin{tabular}{|llllllllll|}
\hline $\begin{array}{l}\text { Target } \\
\text { protein }\end{array}$ & $\begin{array}{l}\text { Type of } \\
\text { tissue }\end{array}$ & \multicolumn{3}{l}{$\begin{array}{l}\text { Number of cases at all } \\
\text { levels }\end{array}$} & $\begin{array}{l}\text { Positive rate } \\
(\%)\end{array}$ & $\begin{array}{l}\text { Total } \\
\text { number }\end{array}$ & $Z$ & $P$ \\
\cline { 2 - 10 } & - & + & $2+$ & $3+$ & & & & \\
\hline DHX15 & BL & 10 & 8 & 6 & 7 & 67.74 & 31 & -4.334 & $<0.001$ \\
& LRH & 26 & 6 & 0 & 0 & 18.75 & 32 & & \\
\hline
\end{tabular}

Silencing DHX15 downregulated the expression of EBNA-1, EBER-1, EBER-2 and RNA pol $\triangle$ transcripts in Raji cells.

We used lentiviral vector-mediated RNAi technique to specifically silence $D H X 15$ gene in Raji cells. After lentiviral transfection, most of the cells were GFP-positive in the NC and KD group, indicating a high efficiency of shRNA transfection (Figure 2A). Lentiviral-mediated DHX15 shRNA significantly silenced DHX15 gene expression in Raji cells compared to NC group (Figure 2B and 2C). Simultaneously, the expression of EBNA-1 mRNA and protein, EBER-1, EBER-2 and RNA pol $₫$ transcripts 5S RNA, 7SL RNA and tRNA ${ }^{\text {tyr }}$ was decreased significantly in the KD group (Figure 2D), indicating that the activity of RNA pol $\square$ was decreased significantly after $D H X 15$ gene knockdown.

Inhibition of DHX15 induced tumor-suppressive properties in Raji cells.

To study the tumor-promotive properties of DHX15 in Raji cells, cell cycle, cell proliferation and cell apoptosis were analyzed after $D H X 15$ gene knockdown. As shown in Figure 3A and 3B, the percentage of cells at the G1 stage was significantly lower in KD group than that in NC group, and the percentage of cells at the $\mathrm{G} 2$ stage in KD group was significantly higher than that in NC group. These data indicated that $D H X 15$ gene knockdown arrested cell cycle at the $\mathrm{G} 2 / \mathrm{M}$ phase. Further study showed that the expression of cyclin B1 and p-CDK1 (Thr161) protein, which could form maturation/mitosis-promoting factor (MPF) and promote cell cycle from G2 to M stage, was decreased significantly after $D H X 15$ gene knockdown (Figure 3C).

Cell proliferation was analyzed by CCK-8 assay, results of which indicated that the OD value of KD group was significantly lower than that of NC group at $72 \mathrm{~h}$ and $96 \mathrm{~h}$ (Figure 3D), indicating that $D H X 15$ gene knockdown inhibited Raji cell proliferation. Simultaneously, the expression of c-myc and survivin was decreased significantly in KD group compared to NC group (Figure 3E).

As shown in Figure $4 A$ and $4 B$, the percentage of apoptotic cells in $K D$ group was significantly higher than that in NC group. Western Blot analysis showed that the ratio of $\mathrm{Bcl}-2 / \mathrm{Bax}, \mathrm{Bcl}-\mathrm{xl} / \mathrm{Bax}$ were significantly decreased after $D H X 15$ gene knockdown (Figure 4C). After pretreatment with Z-VAD-fmk, the percentage of apoptotic cells in $\mathrm{KD}+Z$ group was decreased significantly compared with $\mathrm{KD}$ group; however, it was still significantly higher than that in $\mathrm{CON}+\mathrm{Z}$ group (Figure $4 \mathrm{D}$ and $4 \mathrm{E}$ ). 
Mitochondria, Caspase cascade and NF-KB signaling pathway were affected after DHX15 silencing in Raji cells.

To determine the role of mitochondria, Caspase cascade and NF-KB signaling pathway in the apoptosis induced by DHX15 silencing, MTP, mitochondrial apoptotic pathway and NF-KB signaling pathway were analyzed. As shown in Figure 5A and 5B, the percentage of cells with higher MTP in KD group was significantly lower than NC group and the percentage of cells of lower MTP in KD group was significantly higher than NC group, indicating that $D H X 15$ gene knockdown induced the decrease of MTP. Further study showed that the expression of mitochondrial cytochrome $C$ was also decreased significantly and the expression of cytoplasmic cytochrome $\mathrm{C}$ was increased significantly after $D H X 15$ gene knockdown, indicating that cytochrome $C$ was released from mitochondria to cytoplasm (Figure 5C).

As shown in Figure 5D, the expression of Caspase 9, Caspase 3, Caspase 7 and PARP was decreased significantly and their corresponding cleaved variants were increased except cleaved PARP after DHX15 gene knockdown. After pretreatment with Z-VAD-fmk, the expression of Caspase 9, Caspase 3, Caspase 7 and PARP in the $K D+Z$ group was increased significantly and their corresponding cleaved variants was decreased except cleaved PARP without differences compared to KD group (Figure 5E), indicating that the Caspase cascade participates in the apoptosis after $D H X 15$ gene knockdown.

As shown in Figure 5F and 5G, the expression of overall P65, phosphorylated P65, nuclear P65 and cytoplasmic P65 was significantly decreased after knockdown of $D H X 15$ gene, indicating that the P65 protein synthesis, activation and translocation into nucleus were inhibited. In addition, a significant decreased in the expression of P-IKKa/ $\beta$, IKKa, IKK $, \mathrm{N}-\mathrm{IKBa}, \mathrm{C}-\mathrm{IKBa}, \mathrm{P}-\mathrm{IKBa}$ occurred as $D H X 15$ gene was downregulated, indicating that the activity of IKK, being responsible for catalyzing IKBa phosphorylation, was inhibited, which finally led to reduced IKBa degradation. Moreover, the expression of P105 and P50 was decreased significantly with no change of P100/P52 expression after knockdown of DHX15 gene, suggesting that the synthesis and activation of P105 protein was reduced.

Silencing DHX15 downregulated the expression of EBNA-1, EBER-1, EBER-2 and RNA pol $₫$ transcripts in Daudi cells.

We used lentiviral vector-mediated RNAi technique to specifically silence $D H X 15$ gene in Daudi cells. After lentiviral transfection, most of the cells were GFP-positive in the NC and KD group, indicating a high efficiency of shRNA transfection (Figure 6A). Lentiviral-mediated DHX15 shRNA significantly silenced DHX15 gene expression in Daudi cells compared to NC group (Figure 6B). Simultaneously, the expression of EBNA-1 mRNA and protein, EBER-1, EBER-2 was decreased significantly in the KD group (Figure 6C and $6 \mathrm{D})$.

Inhibition of DHX15 induced tumor-suppressive properties in Daudi cells.

To study the tumor-promotive properties of DHX15 in Daudi cells, cell cycle, cell proliferation and cell apoptosis were analyzed after $D H X 15$ gene knockdown. As shown in Figure 6E and 6F, the percentage of 
cells at the $\mathrm{G} 1$ stage was significantly higher in KD group than that in NC group, and the percentage of cells at the $\mathrm{G} 2$ stage in KD group was significantly lower than that in NC group. These data indicated that DHX15 gene knockdown arrested cell cycle at the G1 phase.

As shown in Figure $6 \mathrm{G}$ and $6 \mathrm{H}$, the percentage of apoptotic cells in $\mathrm{KD}$ group was significantly higher than that in NC group. Western Blot analysis showed that the ratio of $\mathrm{Bcl}-2 / \mathrm{Bax}, \mathrm{Bcl}-\mathrm{xl} / \mathrm{Bax}$ were significantly decreased after $D H X 15$ gene knockdown (Figure 6J).

Cell proliferation was analyzed by CCK-8 assay, results of which indicated that the OD value of KD group was significantly lower than that of NC group at $48 \mathrm{~h}, 72 \mathrm{~h}$ and $96 \mathrm{~h}$ (Figure 6l), indicating that DHX15 gene knockdown inhibited Daudi cell proliferation.

DHX15 silencing inhibited in vivo BL xenograft tumor formation.

To further study the effects of $D H X 15$ gene knockdown on the tumorigenic phenotype of $B L$ and its contribution to tumor growth in vivo, we successfully established a xenograft model of human BL. All nude mice could be detected with subcutaneous transplanted tumor growth. The photographic image of xenograft tumors dissected from the nude mice was shown in Figure 7A. The xenograft tumors in the KD group were significantly smaller and lighter than that in the CON and NC group (Figure 7B, Supplementary Table 2). These data indicated that $D H X 15$ gene knockdown inhibited xenograft tumors growth in vivo.

\section{HE staining}

Routine HE staining was conducted after tissue section. As shown in Figure 7C, the tumor cells in the CON group were closely aligned, with larger cell size, larger nuclei and deeper staining, and fewer cytoplasm. The tumor cells in the NC group were slightly looser than the CON group. The cell volume was larger, the nucleus was larger and deeper, the cytoplasm and blood vessels were red, and a small amount of necrotic tissue was found in the NC group. In the KD group, the tumor cells in the transplanted tumor tissue were arranged sparsely and the nuclei were narrowed. The chromatin was assembled, condensed, thickened and dyeing deepened. The apoptotic bodies appeared and many apoptotic cells and necrotic foci were found. These data indicated $D H X 15$ gene knockdown inhibited xenograft tumors growth and promoted apoptosis in microanatomy.

Suppression of DHX15 induced apoptosis in vivo.

TUNEL IHC analysis was performed to determine the apoptosis of xenograft tumors in each group. As shown in Figure 7D and Table 3, the proportion of cells with nucleus staining yellowish-brown in the KD group was significantly higher than the CON and NC group, indicating that $D H X 15$ gene knockdown promoted apoptosis of Raji cells in xenograft tumors. 
Table 3

Comparison of TUNEL results in tumor tissues of each group

\begin{tabular}{|llllllll|}
\hline Group & $\mathbf{n}$ & Positive Rate (\%) & $\boldsymbol{F}$ & $\boldsymbol{P}$ & Score & $\boldsymbol{F}$ & $\boldsymbol{P}$ \\
\hline CON & 3 & $5.87 \pm 2.06$ & & & $1.00 \pm 0$ & \\
\hline NC & 3 & $5.00 \pm 2.85$ & & & $1.00 \pm 0$ & \\
\hline KD & 3 & $14.53 \pm 4.38$ & 7.926 & 0.021 & $1.00 \pm 0$ & - & - \\
\hline
\end{tabular}

Suppression of DHX15 downregulated EBNA-1, EBER-1, EBER-2 and Ki-67 in vivo.

IHC was performed to determine protein levels of DHX15, EBNA-1 and Ki-67 of xenograft tumors in each group. As shown in Figure 7D and Table 4, the positive rate of DHX15 and EBNA-1 and their corresponding IHC integral in the KD group were significantly lower than the CON and NC group. The positive rate of $\mathrm{Ki}-67$, which reflected the cell proliferation activity, in the KD group was also significantly lower than the $\mathrm{CON}$ and NC group, but there was no significant difference of IHC integral between the three groups (Figure 7D, Table 4).

Table 4

Comparison of DHX15, EBNA-1, Ki-67 protein positive rate and IHC score in tumor tissues of each group

\begin{tabular}{|lllllllll|}
\hline Target Protein & Group & $\mathbf{n}$ & Positive Rate(\%) & $\boldsymbol{F}$ & $\boldsymbol{P}$ & IHC Score & $\boldsymbol{F}$ & $\boldsymbol{P}$ \\
\hline DHX15 & CON & 3 & $23.37 \pm 6.39$ & & & $1.33 \pm 0.58$ & & \\
\hline & NC & 3 & $30.73 \pm 5.20$ & & & $2.67 \pm 1.15$ & & \\
\hline KD & 3 & $2.23 \pm 3.87$ & 26.350 & 0.001 & $0.33 \pm 0.58$ & 6.167 & 0.035 \\
\hline EBNA-1 & CON & 3 & $50.70 \pm 22.11$ & & & $4.67 \pm 1.15$ & & \\
\hline & NC & 3 & $48.57 \pm 12.19$ & & & $3.33 \pm 2.31$ & & \\
\hline Ki-67 & KD & 3 & $11.37 \pm 10.64$ & 5.864 & 0.039 & $0.67 \pm 0.58$ & 5.333 & 0.047 \\
\hline & CON & 3 & $35.80 \pm 4.37$ & & & $2.67 \pm 1.15$ & & \\
\hline NC & 3 & $34.50 \pm 5.90$ & & & $2.00 \pm 0.00$ & & \\
\hline
\end{tabular}

EBER-ISH analysis was performed to determine the expression of EBER-1 and EBER-2 of xenograft tumors in each group. As shown in Figure 7D and 7E, the OD value, which was proportional to the EBER level in tumor tissue, in KD group was significantly lower than that in CON and NC group. These data indicated that $D H X 15$ gene knockdown inhibited the expression of type $\otimes \mathrm{EBV}$ latent infection products in vivo.

\section{Discussion}


In this study, we firstly detected overexpression of DHX15, a member of the DEAH-box RNA helicase family in $\mathrm{BL}$ patients. Then we explored the effect of $D H X 15$ gene knockdown on $\mathrm{BL}$ both in vivo and in vitro. In the meantime, it is the first time to study the relationship between DHX15 and EBV. In accordance with our previous study, DHX15 gene knockdown significantly induced cell apoptosis and cell cycle arrest, inhibited cell proliferation and growth of subcutaneous transplanted tumors in BL cells.

The transcription factor NF-KB is a key player in the inflammation, cancer development and progression $(21-22)$. Aberrant NF-KB activation is a characteristic of various human malignances $(21,23)$. Activated NF-KB can stimulate cell proliferation, prevent apoptosis, and promote tumor angiogenesis, epithelial-tomesenchymal transition (EMT), invasiveness, as well as metastasis (24-25). Previous studies have found that constitutive NF-KB activation was involved in the pathogenesis of BL and NF-KB seemed to be required for the constitutive activation of c-myc and the upregulation of c-myc (26-28). In our experiments, we found that $D H X 15$ gene knockdown inhibited the canonical NF-KB signaling pathway possibly via the following aspects: (1) inhibiting the synthesis and phosphorylation of p65/RelA protein, (2) inhibiting IKB kinase (IKK) to reduce the phosphorylation and proteasome-mediated degradation of IKBa, (3) inhibiting the activation of p105/NF-KB1 protein. Finally, DHX15 gene knockdown inhibited the homodimer or heterodimer formation of $\mathrm{p} 65$ with $\mathrm{p} 50$, leading to reduced translocation into the nucleus and subsequent inhibition of the transcription of target genes. We also found that there was no significant change in p100/NF-KB2 protein level, a member of the non-canonical NF-kB signaling pathway. However, whether $D H X 15$ gene affects the non-canonical NF-KB signaling pathway is unclear and requires further study.

Several studies reported that DHX15 activates p38 MAPK and NF-KB signaling pathway during anti-virus infection (11-12). In our study, we found that the activity of NF-KB signaling pathway and its downstream targets, including Bcl-2, Bcl-xl, survivin, were downregulated after $D H X 15$ gene knockdown, indicating that $D H X 15$ gene knockdown may affect the function of mitochondria via Bcl-2 family members. Subsequent studies confirmed the hypothesis that MTP was decreased and cytochrome $C$ was released from mitochondria to cytoplasm, which activated the mitochondrial apoptotic pathway leading to Raji cells apoptosis. The above results suggested that mitochondria and Caspase cascade are involved in apoptosis after $D H X 15$ gene knockdown in Raji cells. What's more, we also found that the apoptosis rate of the Z-VAD-fmk pretreatment group was significantly higher than that of control group. The reasons we speculate are as follows: First, there may be other pathways that participate in cell apoptosis besides Caspase cascade, such as apoptosis inducing factor (AIF) signaling pathway (29-30), Bcl-2 inhibitor of transcription 1 (Bit1) signaling pathway (31). Second, the combination of the inhibitor and its substrate has a saturation effect, and Z-VAD-fmk cannot inhibit Caspase activity completely, which is also the cause of the higher cell apoptosis rate in the Z-VAD-fmk pretreatment group than that in control group. In addition, whether exogenous apoptotic pathways Caspase 8 or Caspase 10 participates in apoptosis needs to be further studied.

EBV, belonging to a family of human herpesviruses, contributes to life-long latent infection in $B$ lymphocytes after primary infection (32). The virus is associated with various human malignancies, such 
as $\mathrm{BL}$, nasopharyngeal carcinoma and Hodgkin lymphoma, which could be detected in almost all samples of endemic BL patients (33). In most BL patients, EBV shows type $\$ latent infection with expression of EBNA-1, EBER-1, EBER-2 and BART microRNAs (34). Previous studies had confirmed that EBV latent infection products EBNA-1, EBER-1 and EBER-2 were closely related to the occurrence and development of $B L$, and they could promote $B L$ cell proliferation and inhibit $B L$ cell apoptosis (6-9). In our study, we found that the expression of EBNA-1, EBER-1, EBER-2 and RNA polymerase $\otimes$ transcripts $5 S$ RNA, 7SL RNA and tRNA ${ }^{\text {tyr }}$ are downregulated after $D H X 15$ gene knockdown, which indicated that DHX15

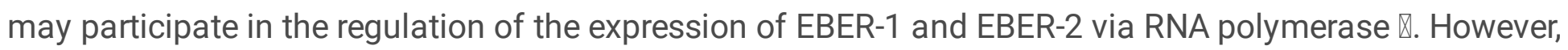

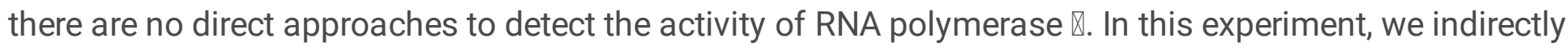
estimated the activity of RNA polymerase $\otimes$ by the level of specific transcripts of RNA polymerase $\nabla$. Therefore, the methodology of direct detection of RNA polymerase $\nabla$ activity needs to be further evaluated. In a word, DHX15 may participate in the occurrence and development of BL via regulation of the expression of the above EBV latent infection products.

Moreover, we found that $D H X 15$ gene knockdown inhibited tumor growth and downregulated EBNA-1, EBER-1, EBER-2 in vivo. The tumor volume and weight of KD group were significantly smaller and lighter than those of the CON and NC group. Our results demonstrated that DHX15 could promoted tumor growth and upregulated EBV latent infection products.

In this study, we revealed that, compared with patients with low DHX15 expression, the overall survival time and progression-free survival time of patients with high DHX15 expression tended to shorten, but there was no significant difference. The reasons we speculate are as follows: First, the number of patients was relatively small because of low incidence rate. Second, the observation time was insufficient. Third, the patients in the group had a long-time span with different treatment options and compliance, for example, in the early years, patients with poor efficacy mostly used the CHOP chemotherapy regimen.

In summary, silencing $D H X 15$ gene could promote $\mathrm{BL}$ cells apoptosis, inhibit cell proliferation in vitro and $B L$ tumor growth in vivo, indicating that DHX15 might be a novel therapeutic target of the treatment for BL. However, there are still some limitations in our study. For example, we did not determine whether DHX15 could also promote the expression of EBV latent infection products in other EBV-associated tumors or whether DHX15 can be used as a target for treatment of latent EBV infection. Further studies are required to explore the underlying mechanisms.

\section{Conclusion}

DHX15 was overexpressed in patients with Burkitt lymphoma and downregulation of $D H X 15$ gene promoted BL cells apoptosis, inhibited cell proliferation and BL tumor growth in vivo, suggesting that $D H X 15$ might be a novel therapeutic target for the treatment of Burkitt lymphoma. 


\section{Clinical Perspectives}

Burkitt lymphoma $(\mathrm{BL})$ is a highly aggressive non-Hodgkin lymphoma and of which Epstein-Barr virus (EBV) and constitutive expression of C-MYC protein play an important role in the development.

Knockdown of DHX15 could inhibit BL tumor growth, cell proliferation as well as the expression of latent EBV infection products and c-MYC protein.

DHX15 might be a novel therapeutic target for the treatment of BL and latent EBV infection.

\section{Abbreviations}




\begin{tabular}{|c|c|}
\hline $\mathrm{BL}$ & Burkitt lymphoma \\
\hline PFS & Progression free survival \\
\hline OS & Overall survival \\
\hline EBV & Epstein-Barr virus \\
\hline $\mathrm{NHL}$ & Non-Hodgkin lymphoma \\
\hline EBNA & EBV-encoded nuclear antigen \\
\hline EBER & EBV-encoded small RNA \\
\hline LMP & Latent membrane protein \\
\hline ALL & Acute lymphoblastic leukemia \\
\hline AML & Acute myeloid leukemia \\
\hline LRH & Lymphoid reactive hyperplasia \\
\hline $\mathrm{IHC}$ & Immunohistochemistry \\
\hline $\mathrm{MOI}$ & Multiplicy of infection \\
\hline PBS & Phosphate buffer solution \\
\hline qRT-PCR & Quantitative real-time PCR \\
\hline CCK-8 & Cell counting kit-8 \\
\hline OD & Optical density \\
\hline MTP & Mitochondrial transmembrane potential \\
\hline NF-KB & Nuclear factor кB \\
\hline IKB & Inhibitor of $\mathrm{kB}$ \\
\hline $\mathrm{N}-\mathrm{I} \mathrm{KBa}$ & Amino-terminal IKBa \\
\hline C-ІкBa & Carboxy-terminal IkBa \\
\hline IKK & IKB kinase \\
\hline HE & Hematoxylin-Eosin \\
\hline TdT & Terminal deoxynucleotidyl transferase \\
\hline TUNEL & TdT mediated nick end labeling \\
\hline ISH & In suit hybridization \\
\hline
\end{tabular}




\section{Declarations}

\section{Ethical Approval and Consent to participate}

The study protocol was approved by the Fujian Medical University Ethics Committee and complied with country-specific regulatory requirements. The study was conducted in accordance with the Declaration of Helsinki and Good Clinical Practice guidelines. Patients provide informed consent authorizing the use of their personal information for research purposes. Our animal experiments were approved by the Laboratory Animal Center at Fujian Medical University.

\section{Consent for publication}

Not applicable.

\section{Availability of data and material}

Y. Chen and S.Y. Wang had full access to all the data in the study (available upon data specific request). Although all our data is de-identified, we opt not to share the data and materials in public due to further study on this subject. However, we will share the data in request by other researchers if necessary. All of the methods including the software programs or reagents used in this study are on the market, which are accessible by other researchers.

\section{Competing interests}

The authors declare that they have no competing interests.

\section{Funding}

This work was supported by the National Natural Science Foundation of China $(81770163,81470008$, 81270609 and 81500139), Fujian Province Health Education Joint Research Project (WKJ-2016-2-07), Special Funding of Fujian Provincial Department of Finance (2017-655), Construction project of Fujian medical center of hematology (Min201704) and was sponsored by National and Fujian Province Key Clinical Specialty Discipline Construction Program, P. R. C.

\section{Authors' contributions}

All authors contributed to analysis and writing the manuscript. Y. Chen and S.Y. Wang designed the research. Y. Chen acquired data and first analyzed the data. X.L. Chen, J.G. Li and Y. Li helped to modify and improve tables and figures. L.L. Pan, Y.M. Huang and Y.H. Caiassisted in written English. All authors read and approved the final manuscript.

\section{Acknowledgments}

We thank Fujian Institute of Hematology and Laboratory Animal Center of Fujian Medical University for providing technical instruction and assistance. This study was supported by the Natural Science 
Foundation of China (No. 81500139).

\section{References}

1. Burkitt D. A sarcoma involving the jaws in African children. Br J Surg. 1958;46:218-23.

2. Ontiveros EP, Halwani A, Stunz LL, et al A new model of LMP1-MY interaction in B cell lymphoma. Leuk Lymphoma 2014.

3. Epstein MA, Achong BG, Barr YM. Virus particles in cultured lymphoblasts from Burkitt's lymphoma. Lancet. 1964;283:702-3.

4. Henle G, Henle W. Immunofluorescence in cells derived from Burkitt's lymphoma. J Bacteriol. 1966;91:1248-56.

5. Henle G, Henle W. Observations on childhood infections with the epstein-barr virus. J Infect Dis. 1970;121:303-10.

6. Kennedy G, Komano J, Sugden B. Epstein-barr virus provides a survival factor to Burkitt's lymphomas. Proc Natl Acad Sci U S A. 2003;100:14269-74.

7. Hong M, Murai Y, Kutsuna T, Takahashi H, Nomoto K, Cheng C-M, et al. Suppression of Epstein-barr nuclear antigen 1 (EBNA1) by RNA interference inhibits proliferation of EBV-positive Burkitt's lymphoma cells. J Cancer Res Clin Oncol. 2005;132:1-8.

8. Nanbo A, Inoue K, Adachi-Takasawa K, Takada K. Epstein-barr virus RNA confers resistance to interferon-alpha-induced apoptosis in Burkitt's lymphoma. EMBO J. 2002;21:954-65.

9. Samanta M, Iwakiri D, Kanda T, Imaizumi T, Takada K. EB virus-encoded RNAs are recognized by RIGI and activate signaling to induce type I IFN. EMBO J. 2006;25:4207-14.

10. Wang P, Zhu S, Yang L, Cui S, Pan W, Jackson R, et al. Nlrp6 regulates intestinal antiviral innate immunity. Science. 2015;350:826-30.

11. Mosallanejad K, Sekine Y, Ishikura-Kinoshita S, Kumagai K, Nagano T, Matsuzawa A, et al. The deahbox RNA helicase DHX15 activates NF-KB and MAPK signaling downstream of MAVS during antiviral responses. Sci Signal. 2014;7:ra40.

12. Lu H, Lu N, Weng L, Yuan B, Liu Y, Zhang Z. DHX15 senses double-stranded RNA in myeloid dendritic cells. J Immunol. 2014;193:1364-72.

13. Cordin O, Banroques J, Tanner NK, Linder P. The DEAD-box protein family of RNA helicases. Gene. 2006;367:17-37.

14. Tsai RT. Spliceosome disassembly catalyzed by Prp43 and its associated components Ntr1 and Ntr2. Genes Dev. 2005;19:2991-3003.

15. Niu Z, Jin W, Zhang L, Li X. Tumor suppressor RBM5 directly interacts with the DExD/H-box protein DHX15 and stimulates its helicase activity. FEBS Lett. 2012;586:977-83.

16. Leeds NB, Small EC, Hiley SL, Hughes TR, Staley JP. The splicing factor Prp43p, a DEAH box ATPase, functions in ribosome biogenesis. Mol Cell Biol. 2006;26:513-22. 
17. Combs DJ, Nagel RJ, Ares M, Stevens SW. Prp43p is a DEAH-box spliceosome disassembly factor essential for ribosome biogenesis. Mol Cell Biol. 2006;26:523-34.

18. Fouraux MA, Kolkman MJM, van der Heijden A, de Jong AS, van Venrooij WJ, Pruijn GJM. The human La (SS-B) autoantigen interacts with DDX15/hPrp43, a putative DEAH-box RNA helicase. RNA. 2002;8:1428-43.

19. Lili Pan Y, Li HY, Zhang, et al. DHX15 is associated with poor prognosis in acute myeloid leukemia (AML) and regulates cell apoptosis via the NF-kB signaling pathway. Oncotarget. 2017;8(52):8964352.

20. Swerdlow SH. WHO classification of tumours of haematopoietic and lymphoid tissues[J]. WHO classification of tumours. 2008;22008:439.

21. Perkins ND. The diverse and complex roles of NF-kappaB subunits in cancer. Nat Rev Cancer. 2012;12:121-32.

22. Karin M. Nuclear factor-kappaB in cancer development and progression. Nature. 2006;44:431-6.

23. Jost PJ, Ruland J. Aberrant NF-kappaB signaling in lymphoma: mechanism, consequence, and therapeutic implications. Blood. 2007;109:2700-7.

24. Scott DW. Gascoyne RD. The tumor microenvironment in B cell lymphomas. Nat Rev Cancer. 2014;14:517-34.

25. Ben-Neriah Y, Karin M. Inflammation meets cancer, with NF-kappaB as the matchmaker. Nat Immunol. 2011;12:715-23.

26. Tafuku S, Matsuda T, Kawakami H, Tomita M, Yagita H, Mori N. Potential mechanism of resistance to TRAIL-induced apoptosis in Burkitt's lymphoma. Eur J Haematol. 2006;76:64-74.

27. Schlee M, Holzel M, Bernard S, Mailhammer R, Schuhmacher M, Reschke J, et al. C-my activation impairs the NF-kappaB and the interferon response: implication for the pathogenesis of Burkitt's lymphoma. Int J Cancer. 2007;120:1387-95.

28. Kanda K, Hu HM, Zhang L, Grandchamps J, Boxer LM. NF-kappa B activity is required for the deregulation of c-my expression by the immunoglobulin heavy chain enhancer. Bio Chem. 2000;275:32338-46.

29. Gabriel B, Sureau F, Casselyn M, et al. Retroactive pathway involving mitochondria in electroloaded cytochrome c-induced apoptosis. Protective properties of Bcl-2 and Bcl-XL. Cell Res. 2003;289(2):195-210.

30. Li LY, Luo X, Wang X. Endonuclease $G$ is an apoptotic DNase when released from mitochondria. Nature. 2001;412(6842):95-9.

31. Jan Y, Matter M, Pai JT, et al. Amitochondrial Protein, Bitl, mediates apoptosis regulated by integrins and Groueho/TLE ceore Pressors. Cell. 2004;116(5):751-62.

32. Arvey A, Tempera I, Tsai K, Chen H-S, Tikhmyanova N, Klichinsky M, et al. An atlas of the epstein-barr virus transcriptome and epigenome reveals host-virus regulatory interactions. Cell Host Microbe. 2012;12:233-45. 
33. Neri A, Barriga F, Inghirami G, Knowles DM, Neequaye J, et al. Epstein-Barrs virus infection precedes clonal expansion in Burkitt's and acquired immunodeficiency syndrome-associated lymphoma. Blood. 1991;77:1092-95.

34. Kang M-S, Kieff E. Epstein-barr virus latent genes. Exp Mol Med. 2015;47:e131.

\section{Figures}

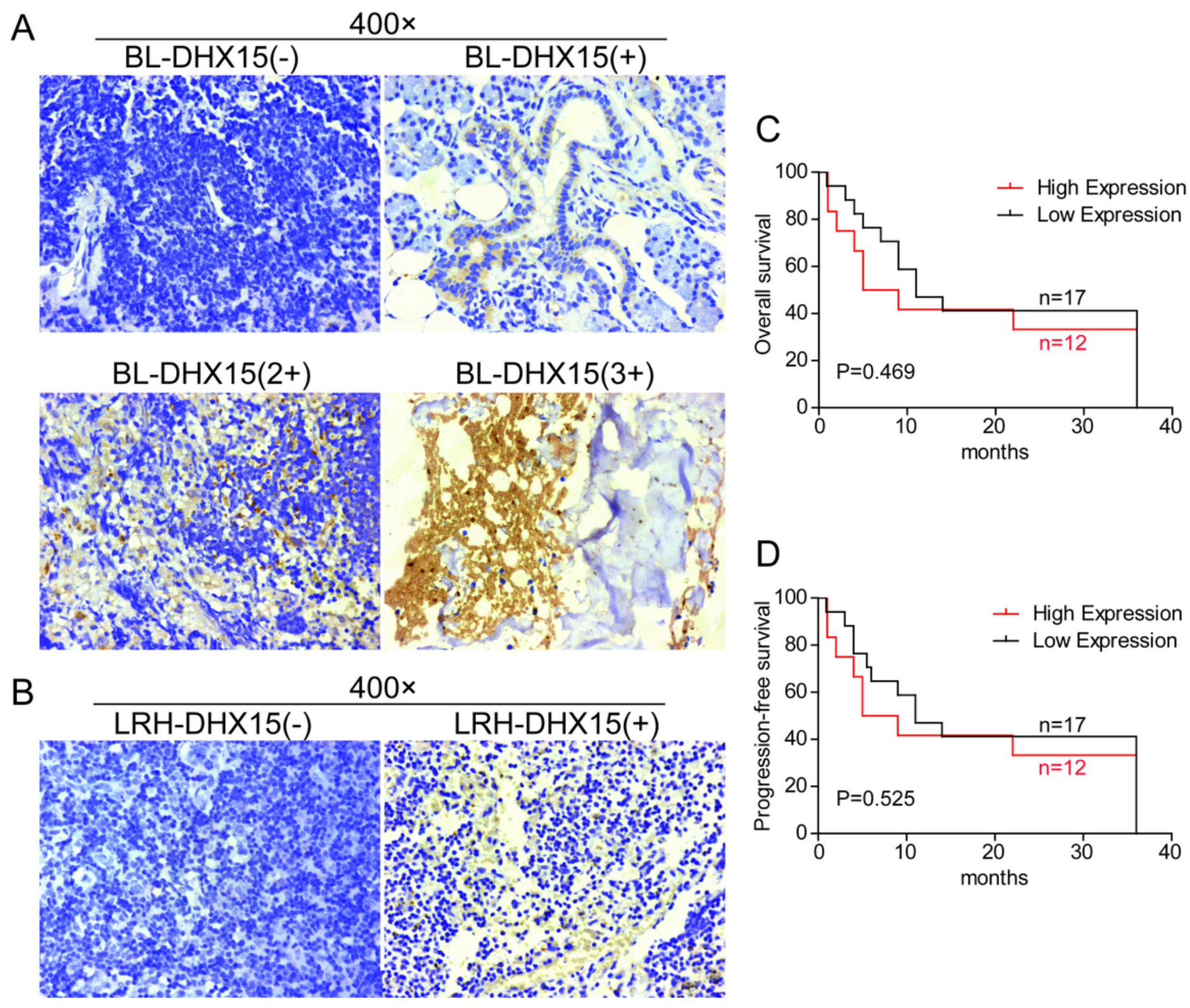

Figure 1

(A) DHX15 staining of tissue sections of BL patients $(\times 400)$. (B) DHX15 staining of tissue sections of noncancer LRH patients $(\times 400)$. (C) Kaplan-Meier analysis for cumulative OS curves of patients with high or low DHX15 expression. The OS time of patients with high DHX15 expression tended to shorten. (D) Kaplan-Meier analysis for cumulative PFS curves of patients with high or low DHX15 expression. The PFS time of patients with high DHX15 expression tended to shorten. 
A Raji (100x)
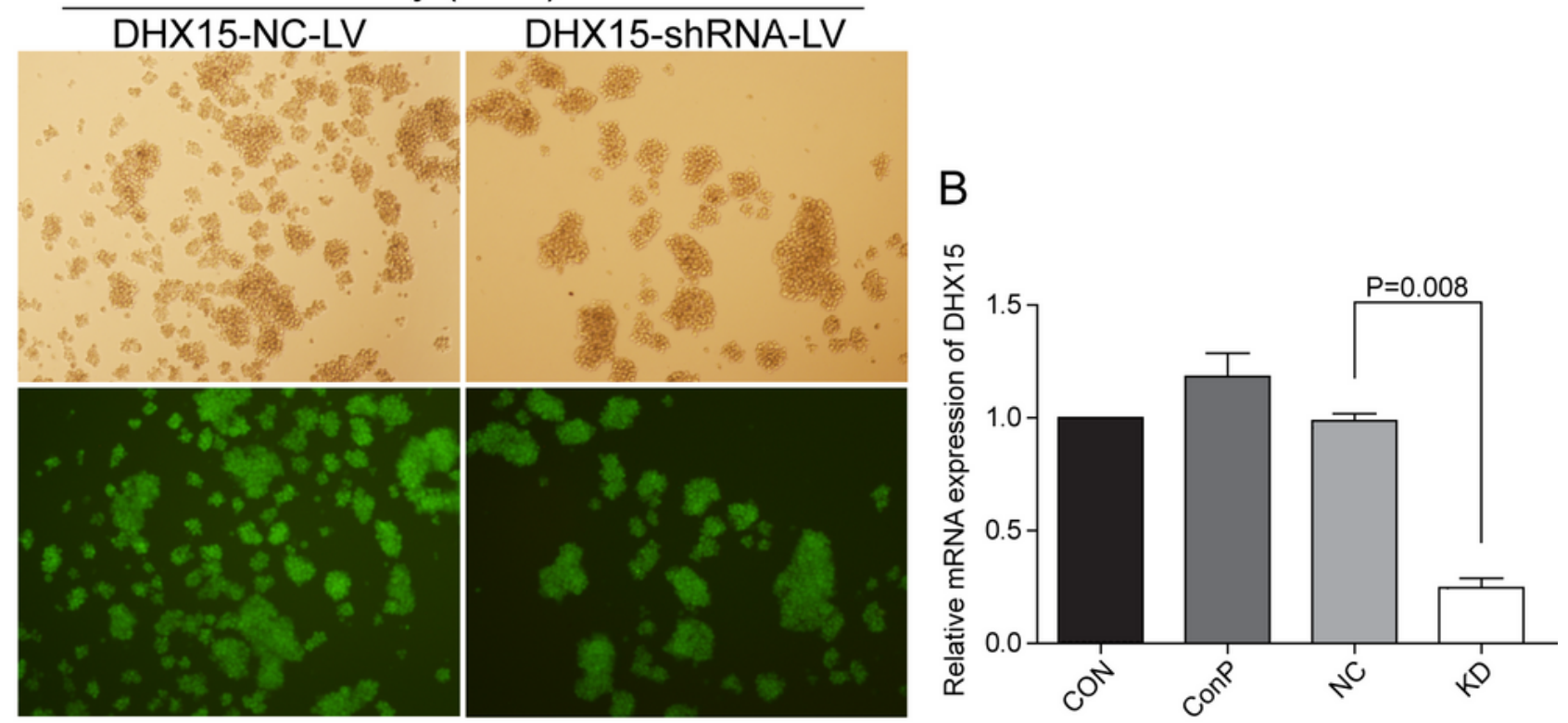

C

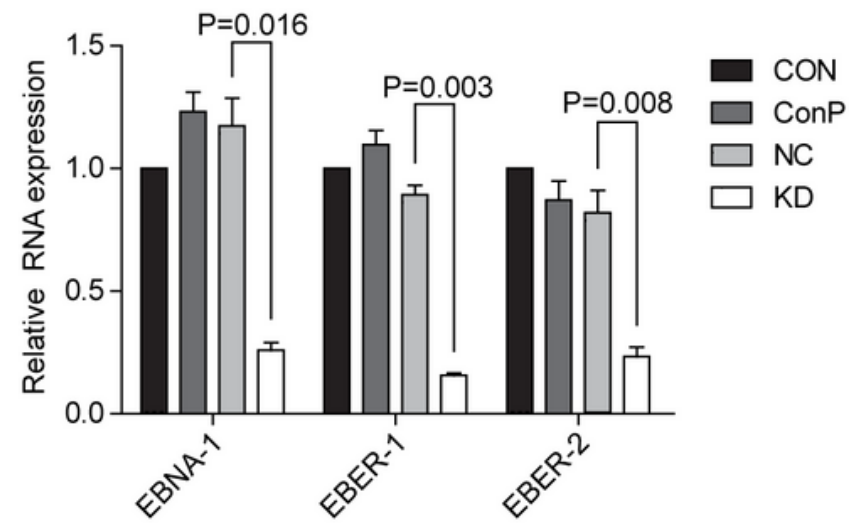

E
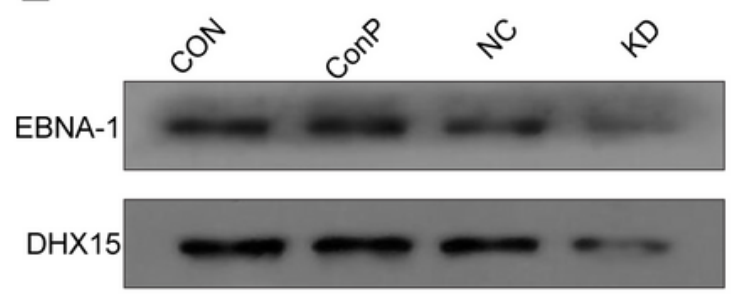

GAPDH

\section{Figure 2}

(A) Infection rate of Raji cells by NC-shRNA-LV and DHX15-shRNA-LV. The top pictures were the result of white light observation, the bottom pictures were the result of corresponding blue light excitation observation, inverted fluorescence microscope $(\times 100)$. (B) QRT-PCR verified DHX15 gene knockdown. Compared with the NC group, ${ }^{*} P=0.008$. (C) Effects of DHX15 gene knockdown on the level of EBNA-1 mRNA, EBER-1 and EBER-2 in Raji cells. Compared with the NC group, ${ }^{*} \mathrm{P}=0.016,{ }^{*} \mathrm{P}=0.003, \# \mathrm{P}=0.008$. 
(D) Effects of DHX15 gene knockdown on the level of 5S RNA, 7SL RNA and tRNAtyr in Raji cells. Compared with the NC group, ${ }^{*}=0.023, * * P=0.001, \# P=0.008$. (E) Effects of $D H X 15$ gene knockdown on protein level of DHX15 and EBNA-1 in Raji cells.

A

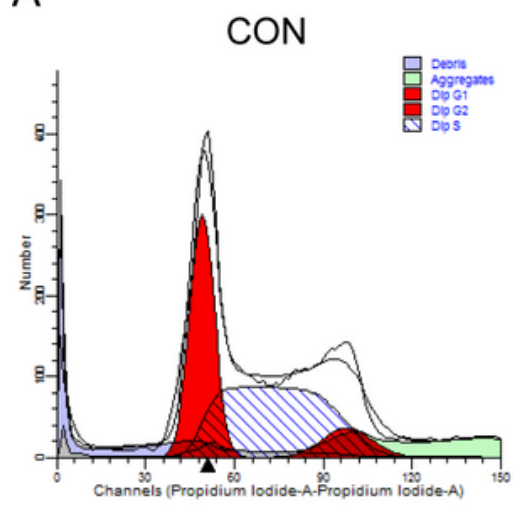

ConP
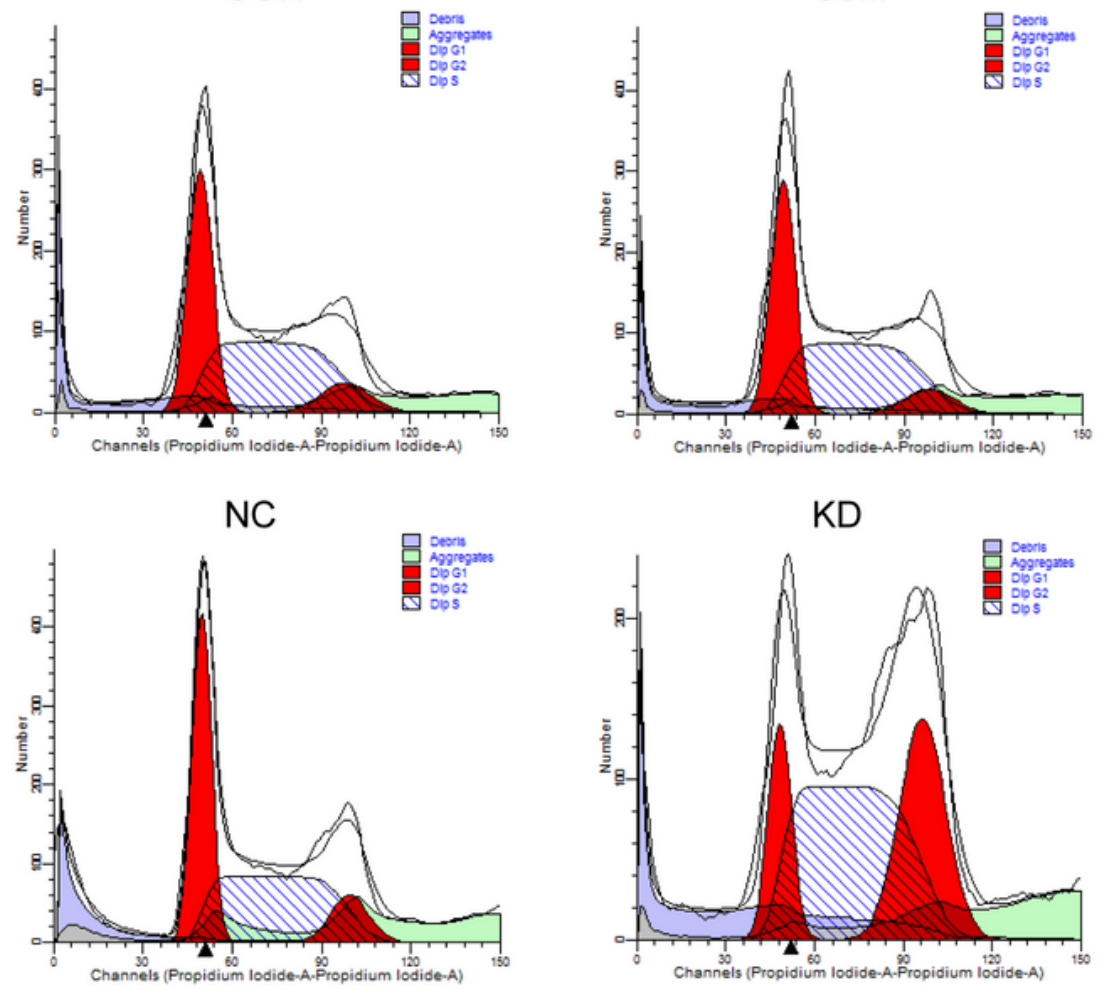

$\mathrm{B}$

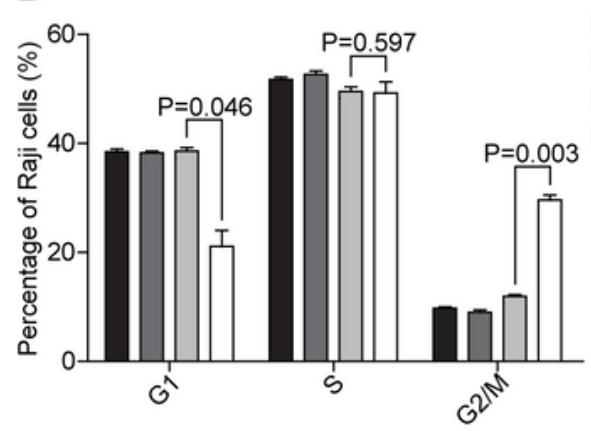

C

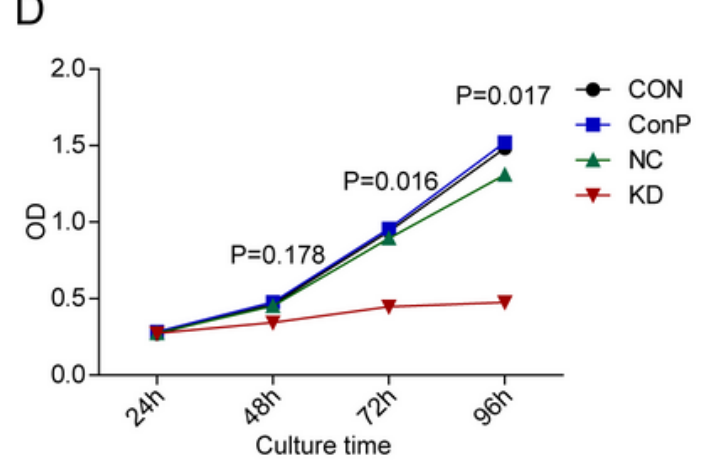

$\mathrm{E}$
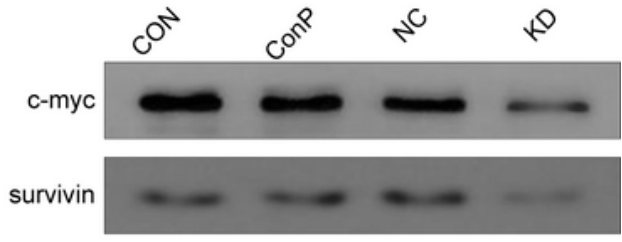

$\beta$-actin
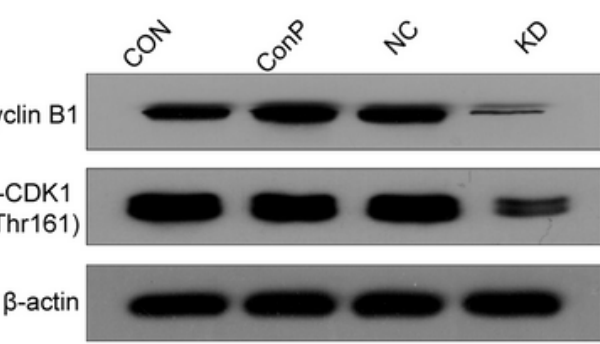

E

B-actin

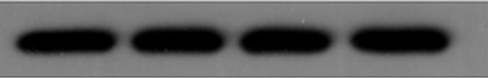

Figure 3

(A), (B) Effects of DHX15 gene knockdown on the cell cycle of Raji cells. Compared with the NC group, ${ }^{*} \mathrm{P}=0.046,{ }^{* *} \mathrm{P}=0.597, \# \mathrm{P}=0.003$. (C) Effects of DHX15 gene knockdown on the protein level of Cyclin B1 
and p-CDK1 (Thr161) of Raji cells. (D) Effects of DHX15 gene knockdown on the proliferation of Raji cells. Compared with NC group, ${ }^{*} \mathrm{P}=0.178,{ }^{\star} \mathrm{P}=0.016, \# \mathrm{P}=0.017$. (E) Effects of $\mathrm{DHX15}$ gene knockdown on the protein level of c-myc and survivin in Raji cells.

A
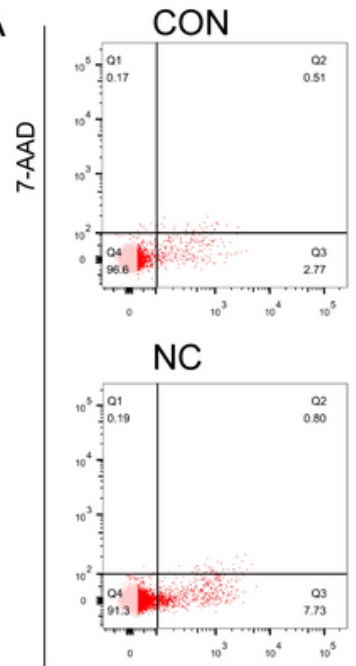

C

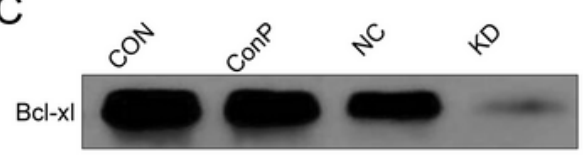

$\mathrm{Bcl}-2$

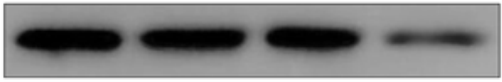

Bax

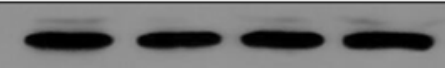

$\beta$-actin

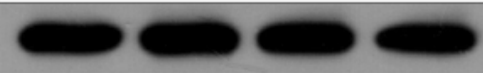

D
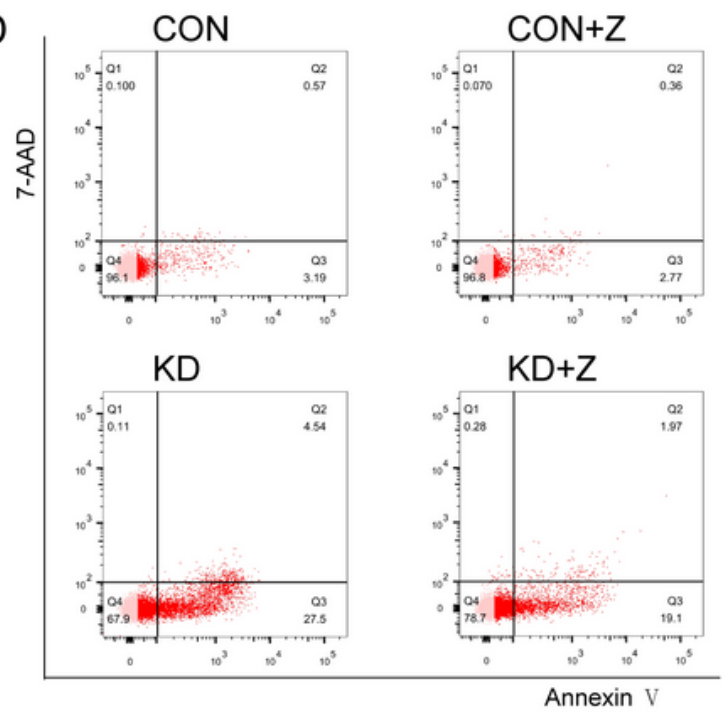

$\mathrm{B}$

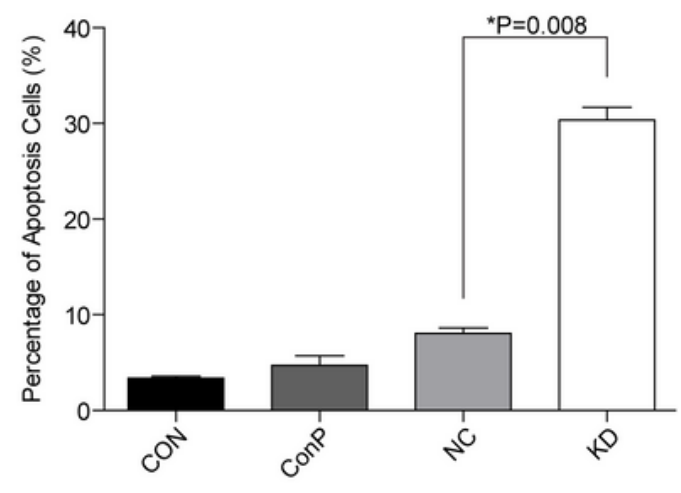

E

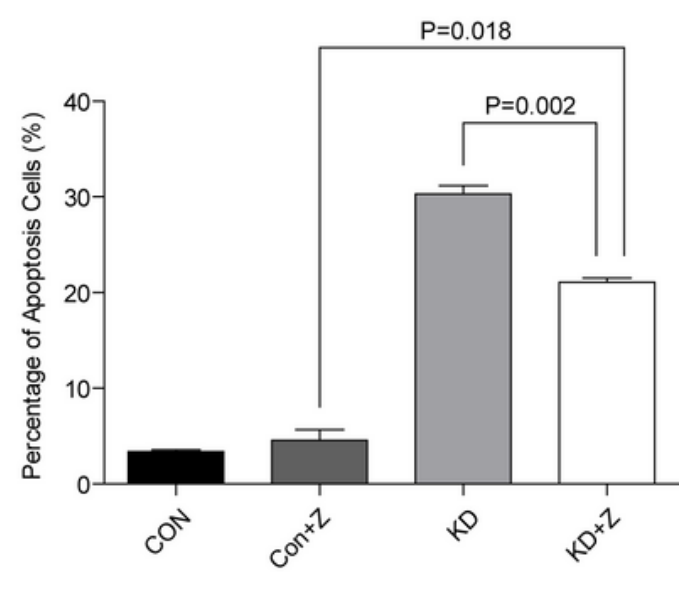

Figure 4

(A), (B) Effects of DHX15 gene knockdown on the apoptosis of Raji cells. Compared with the NC group, ${ }^{*} P=0.008$. (C) Effects of DHX15 gene knockdown on the level of the Bcl-2 family proteins. (D), (E) Effects 
of DHX15 gene knockdown on the apoptosis of Raji cells after Z-VAD-fmk pretreatment. Compared with the KD group, *P=0.002, compared with $\mathrm{CON}+\mathrm{Z}$ group, ${ }^{*} \mathrm{P}=0.018$.

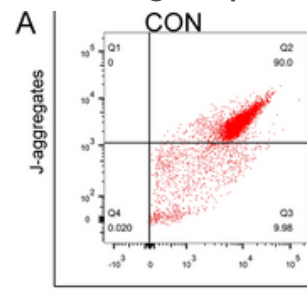

B

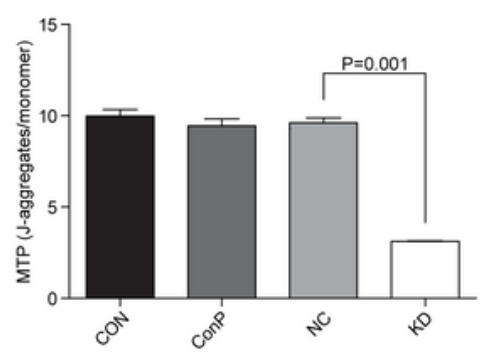

D

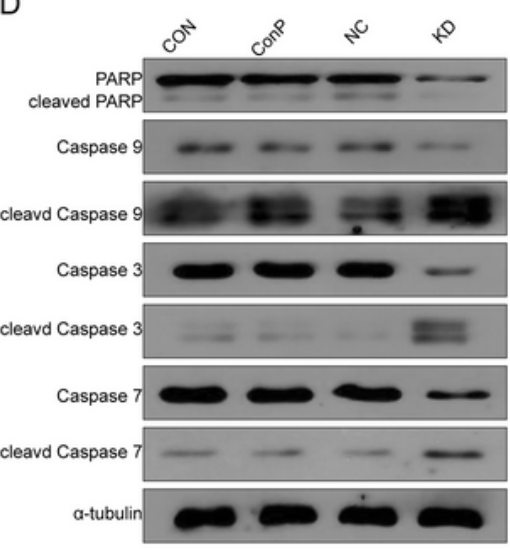

$\mathrm{F}$

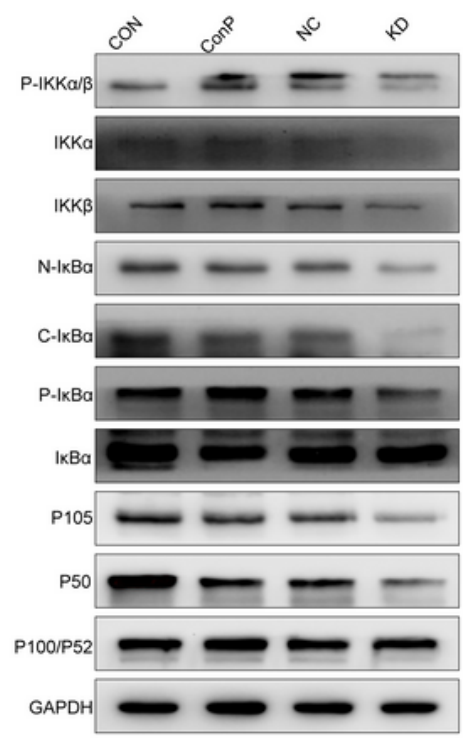

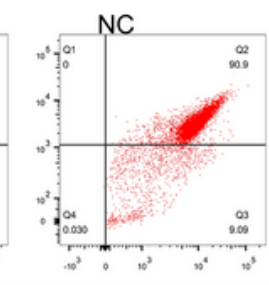

C

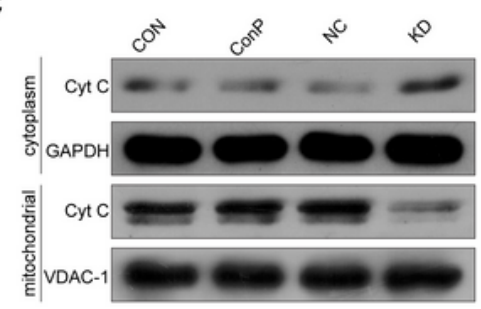

E
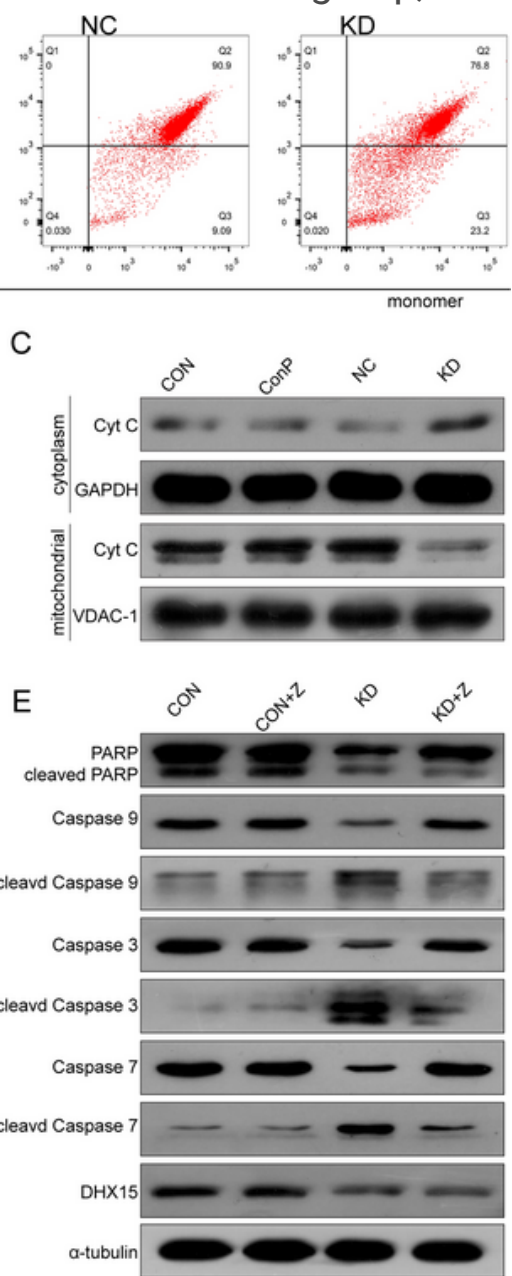

G

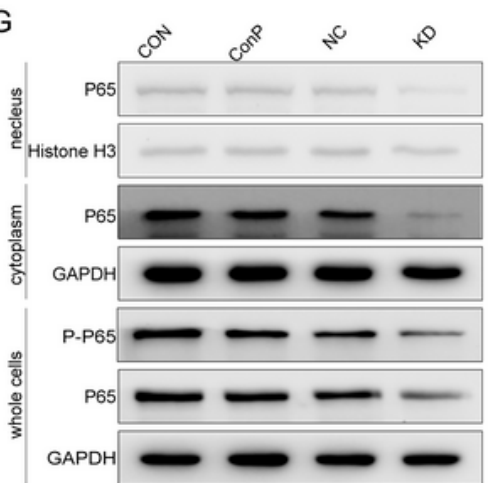

\section{Figure 5}

(A), (B) Effects of DHX15 gene knockdown on the MTP of Raji cells. Compared with the NC group, ${ }^{*} \mathrm{P}=0.001$. (C) Effects of DHX15 gene knockdown on the expression of cytoplasmic cytochrome $\mathrm{C}$ and mitochondrial cytochrome C of Raji cells. (D) Effects of DHX15 gene knockdown on the level of Caspase 
family proteins, PARP and their spliced variants in Raji cells. (E) Effects of DHX15 gene knockdown on the level of Caspase family proteins, PARP and their spliced variants in Raji cells after Z-VAD-fmk pretreatment. (F) Effects of DHX15 gene knockdown on the level of P-IKKa/ $\beta, I K K a, I K K \beta, N-I K B a, C-I K B a$, P-IKBa, IKBa, P105, P50, P100/P52 and P-P65. (G) Effects of DHX15 gene knockdown on the level of nuclear P65, cytoplasmic P65, and overall P65.

A
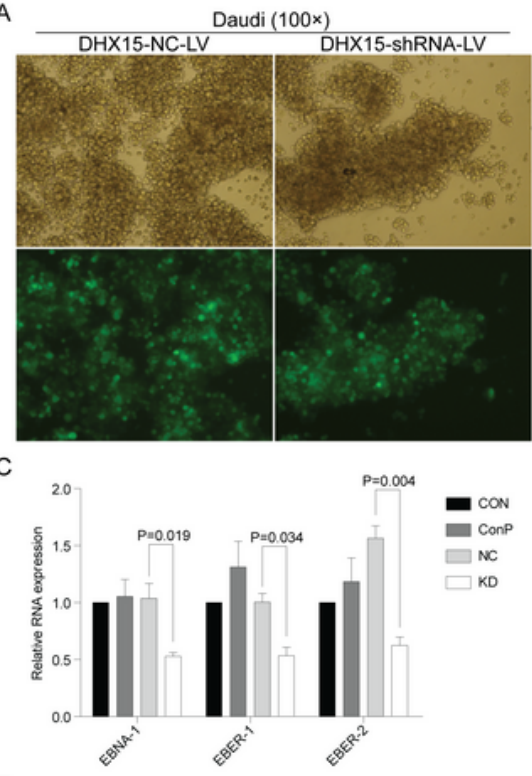

E
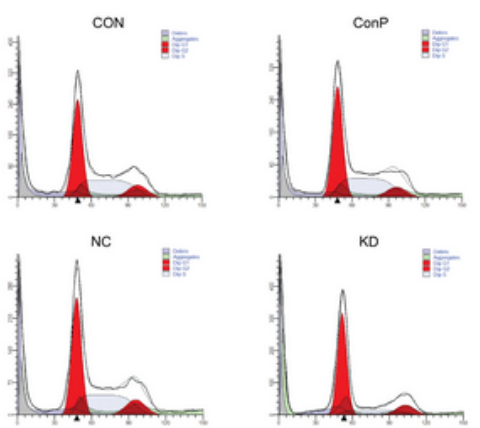

G
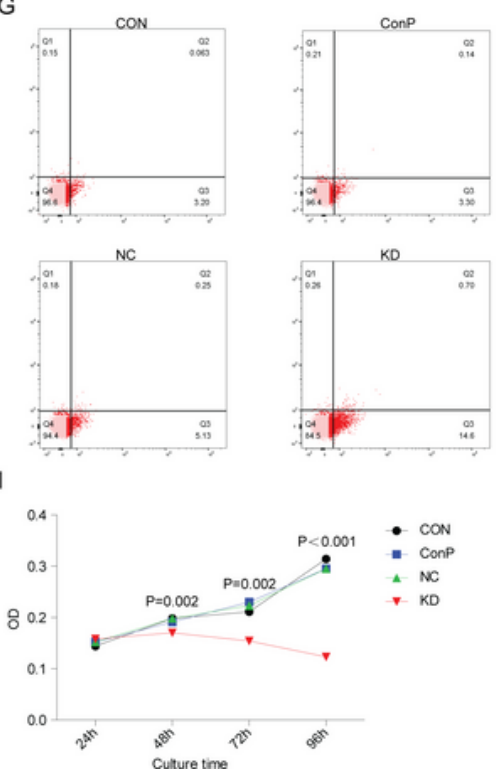

B

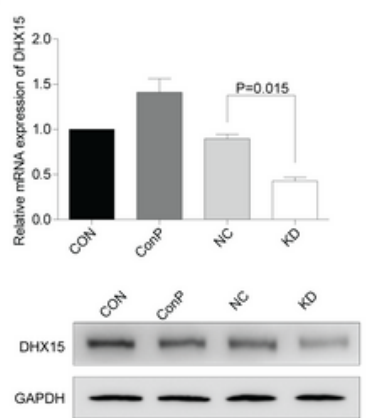

$D$
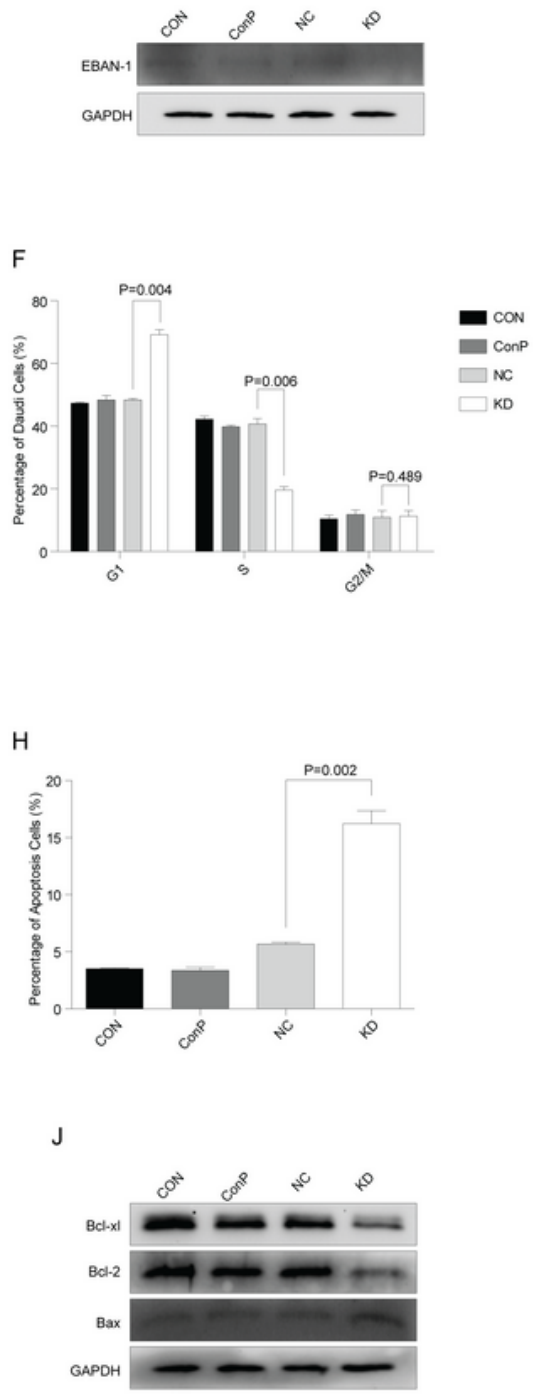

Figure 6 
(A) Infection rate of Daudi cells by NC-shRNA-LV and DHX15-shRNA-LV. The top pictures were the result of white light observation, the bottom pictures were the result of corresponding blue light excitation observation, inverted fluorescence microscope $(\times 100)$. (B) QRT-PCR and Western-blot verified DHX15 gene knockdown. Compared with the NC group, ${ }^{*} P=0.015$. (C) Effects of $D H X 15$ gene knockdown on the level of EBNA-1 mRNA, EBER-1 and EBER-2 in Daudi cells. Compared with the NC group, ${ }^{*}=0.019$, $* * P=0.034$, $\# P=0.004$. (D) Effects of DHX15 gene knockdown on the level of EBNA-1 protein. (E), (F) Effects of DHX15 gene knockdown on the cell cycle of Daudi cells. Compared with the NC group, * $P=0.004$, $\star * P=0.006, \# P=0.489 .(G),(H)$ Effects of DHX15 gene knockdown on the apoptosis of Daudi cells. Compared with the NC group, $* P=0.002$. (I) Effects of DHX15 gene knockdown on the proliferation of Daudi cells. Compared with NC group, ${ }^{*} P=0.002$, ${ }^{*} P=0.002$, \#P<0.001. (J) Effects of DHX15 gene knockdown on the level of the Bcl-2 family proteins in Daudi cells. 


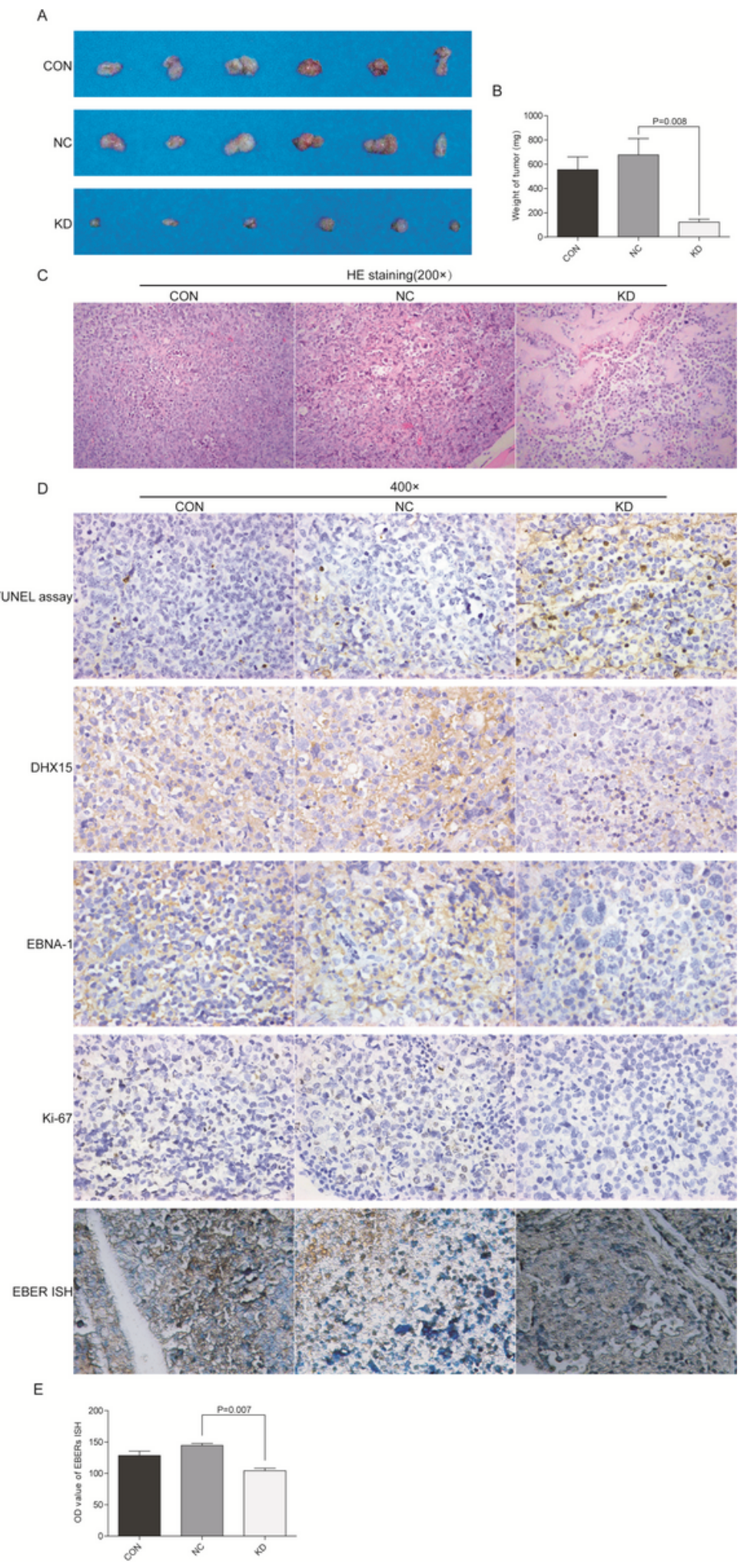

\section{Figure 7}

(A) General view of transplanted tumor in each group. (B) Comparison of tumor quality in each group. Compared with the NC group, $* P=0.008$. (C) Routine HE staining of tumor tissues in each group (200x). (D) TUNEL assay was used to detect apoptosis in tumor tissues (400x). IHC detected DHX15, EBNA-1 and $\mathrm{Ki}-67$ protein in tumor tissues of each group. The expression of DHX15 and EBNA-1 protein can be detected in both the cytoplasm and nucleus (400x). The Ki-67 protein was located in the nucleus (400x). 
Results of EBER in situ hybridization in tumor tissues of each group (400x). (E) Comparison of OD values of EBER in situ hybridization in tumor tissues of each group. Compared with the NC group, ${ }^{*} \mathrm{P}=0.007$

\section{Supplementary Files}

This is a list of supplementary files associated with this preprint. Click to download.

- SupplementaryMaterial.docx 